\title{
Threshold Distinctions Between Equilibrium and Nonequilibrium Pastoral Systems Along a Continuous Climatic Gradient
}

\author{
Tomoo Okayasu, ${ }^{1}$ Toshiya Okuro, ${ }^{2}$ Undarmaa Jamsran, ${ }^{3}$ and Kazubiko Takeuchi ${ }^{4}$
}

\author{
Authors are ${ }^{1}$ Project Research Associate, ${ }^{2}$ Associate Professor, and ${ }^{4}$ Professor, Graduate School of Agricultural and Life Sciences, The University of \\ Tokyo, Yayoi 1-1-1, Bunkyo-ku, Tokyo 113-8657, Japan; and ${ }^{3}$ Associate Professor, Center for Ecosystem Studies, Mongolian State University of \\ Agriculture, Zaisan 53, Ulaanbaatar 210153, Mongolia.
}

\begin{abstract}
In equilibrium environments where rainfall is relatively stable, grazing animal-vegetation dynamics are density-dependent; it is therefore appropriate to calculate carrying capacities and use them to define sustainable animal populations. In contrast, nonequilibrium environments are characterized by fluctuations in characteristics such as rainfall, resulting in fluctuations in plant biomass and in the corresponding carrying capacity. Herders adapt to such environments by moving opportunistically to pastures with better conditions. Studies since the 1990s have significantly improved our understanding of the continuity and integration of equilibrium and nonequilibrium systems. However, it remains unclear how and where such continuous, integrated rangeland systems result in qualitatively different land use patterns by local herders along a climatic gradient. Here, we developed a simple model that uses key environmental factors to predict a threshold representing the boundary between equilibrium and nonequilibrium land use systems, and we used an area of Mongolian rangeland as an example. We found a threshold in the proportion of usable pasture that corresponded to a specific range of rainfall values. Comparison of our results with previous ones supported our hypothesis about this threshold. The threshold behavior suggested that it is important to identify and monitor the boundary between equilibrium and nonequilibrium land use systems so that managers can respond to climatic change. National governments and aid agencies must understand the threshold process before they can identify focal areas where management regime change is required and propose appropriate policies that will support herders in the long term. Our study provides a simple, low-cost tool to evaluate ecosystems in this context.
\end{abstract}

\section{Resumen}

En ambientes en equilibrio en los que las lluvias son relativamente estables, la dinámica que se establece entre animales en pastoreo y la vegetación es denso-dependiente; por lo tanto, resulta apropiado calcular las receptividades y utilizarlas para definir poblaciones animales sustentables. Por otra parte, los ambientes sin un estado claro de equilibrio se caracterizan por fluctuaciones en la precipitación que resultan en fluctuaciones en la biomasa vegetal y en la receptividad del sistema. Los pastores trashumantes se adaptan a estos ambientes moviéndose de modo oportunista a pasturas con mejores condiciones. Estudios realizados desde 1990 han mejorado significativamente nuestra comprensión de la continuidad e integración de sistemas con y sin estados claros de equilibrio. Sin embargo, no resulta claro en qué condiciones o en qué lugares de la continuidad e integración de sistemas de pastizales naturales se generan patrones de uso de la tierra cualitativamente diferentes por parte de pastores locales a lo largo de gradientes climáticos. En este trabajo desarrollamos un modelo sencillo que usa factores ambientales claves para predecir el umbral que representa el límite entre usos de la tierra asociados a condiciones de equilibrio o falta de equilibrio, y utilizamos un área de pastizales de Mongolia como ejemplo. Encontramos un umbral en la proporción de pasturas utilizables que correspondió a un rango específico de valores de precipitación. La comparación de nuestros resultados con estudios previos confirmó nuestra hipótesis sobre este umbral. El comportamiento de umbral (discontinuo) del sistema sugiere que es importante identificar y monitorear el límite entre sistemas de de uso de la tierra asociados a condiciones de presencia o ausencia de equilibrio a fin de que los usuarios de la tierra puedan responder al cambio climático. Los gobiernos y las agencias que proporcionan asistencia deben comprender el proceso de umbral para poder identificar áreas focales en las que se requieren cambios en el régimen de manejo y deben proponer políticas adecuadas que apoyen a los pastores en el largo plazo. Nuestro estudio provee una herramienta sencilla de bajo costo para evaluar ecosistemas en este contexto.

Key Words: Mongolia, nomadic pastoralism, rangeland, Terra MODIS

This study was funded by the Global Environmental Fund of the Ministry of the Environment of Japan (G-71, Desertification Control and Restoration of Ecosystem Services in Grassland Regions of North-East Asia) and by the Global Center of Excellence Program of the Japan Society for the Promotion of Science, Ministry of Education, Culture, Sports, Science, and Technology (Center of Excellence for Asian Conservation Ecology as a Basis of HumanNature Mutualism).

Correspondence: T. Okayasu, Laboratory of Landscape Ecology and Planning, Graduate School of Agricultural and Life Sciences, The University of Tokyo, Yayoi 1-1-1, Bunkyo-ku, Tokyo 1138657, Japan. Email: aokayasu@mail.ecc.u-tokyo.ac.jp

Manuscript received 30 September 2009; manuscript accepted 26 September 2010.

\section{INTRODUCTION}

Rangeland management in an equilibrium rangeland is based on Clementsian succession theory (Clements 1916) and is implemented by controlling livestock numbers below the level that would cause degradation of the ecosystem (i.e., the carrying capacity), while maximizing the productivity of the livestock (Caughley 1979). However, the application of this method to nonequilibrium African rangeland on the basis of destocking (i.e., reducing livestock numbers) to levels below the 
estimated carrying capacity has failed (Hary et al. 1996), thus catalyzing new studies since the 1980s of rangeland management methods suitable for such environments (Ellis and Swift 1988; Behnke and Scoones 1993; Scoones 1996).

Nonequilibrium environments are often characterized by fluctuations in parameters such as rainfall and the resulting fluctuations in biomass (Ellis and Swift 1988). Such unpredictable climates prevent herders from continuously using certain pastures, and these herders have adapted by periodically moving to pastures with better conditions. This strategy is called "opportunistic management" (Danckwerts et al. 1993). The number of animals that can be managed under such conditions is independent of their population density, which suggests that nonequilibrium rangeland is less vulnerable to anthropogenic degradation when the rangeland is used by nomadic herders (Sullivan and Rohde 2002). Many studies have found that the dominant factor that controls vegetation in nonequilibrium rangeland is climate, and that the impact of human disturbance on vegetation conditions is negligible (e.g., Fernandez-Gimenez and Allen-Diaz 1999).

Recognizing the difference between equilibrium and nonequilibrium environments is important, because the most appropriate management strategies differ significantly (Scoones 1996). In an equilibrium environment, the primary goal of rangeland management has been to measure carrying capacity for various uses (Behnke and Scoones 1993). On the basis of the estimated carrying capacity, managers can maximize productivity for uses such as grazing. On the contrary, the goal of nonequilibrium rangeland management is to support the ability of herders to respond to their unpredictable environments by learning how the herders monitor their environment and by using this knowledge to support adaptive management (Scoones 1996). However, uncritical adoption of nonequilibrium solutions can encourage land managers to ignore the need for sustainable management (Watson et al. 1996); this may happen when managers erroneously believe that under nonequilibrium rangeland ecology, human impacts would be negligible (Sullivan and Rohde 2002).

Since the 1990s, many authors have pointed out that the new paradigm for rangeland ecology is too extreme, and that natural rangeland consists of a combination of equilibrium and nonequilibrium systems. Fiedler et al. (1997) proposed the existence of a continuum between equilibrium and nonequilibrium systems; in this hypothesis, the two systems represent the extremes of a continuous range of environments, and any given area of rangeland will lie somewhere between these extremes. Fernandez-Gimenez and Allen-Diaz (1999) provided empirical evidence to support the existence of this continuum, and they confirmed that the impacts of climate and grazing were not mutually exclusive; instead, the relative importance of the two factors changed along the climatic gradient. Illius and O'Connor (1999) proposed an integrated model in which natural equilibrium systems exist even in arid rangeland but are confined within relatively small areas called "key resources." Because the number of animals is limited by these small areas, large areas of wet-season range can become nonequilibrium systems. Illius and O'Connor successfully integrated equilibrium and nonequilibrium systems by introducing the concept of spatial variation in the degree of equilibrium at the landscape level. According to their theory, the degree of equilibrium in wet-season rangelands increases as the climate becomes wetter, and this improves our understanding of how equilibrium and nonequilibrium rangeland form a continuum. Briske et al. (2003) showed that the impact of grazing is significant even in arid rangeland, but that the time scale for this impact to become evident is much longer than that of climatic impacts, which cause arid rangelands to resemble nonequilibrium systems on a typical management time scale. This finding also improved our understanding of the continuity in rangeland systems by accounting for the different time scales of the impacts of climate change and grazing. These studies have therefore provided a better explanation of how arid rangeland can become degraded, and how rangeland management to prevent degradation of the ecosystem is important even in arid rangeland. Moreover, these studies provided more concrete management guidelines for arid rangeland. For example, Illius and O'Connor (1999) summarized the vulnerabilities of various compositions of landscape units to land degradation; the vulnerabilities were derived systematically from their theory.

These studies have significantly improved our understanding of the continuity and integration of equilibrium and nonequilibrium systems in global dryland ecosystems. However, it remains unclear how and where the use of such continuous and integrated rangeland systems will lead to qualitative differences in the pasture use patterns of herders. In relatively humid rangeland, herders have the customary right of exclusive use of an area of pasture (Scoones 1996) and move seasonally among areas, whereas in arid areas, herders use large areas of public land (Perevolotsky 1987) and move their herds opportunistically to find pastures where it has recently rained and that can therefore support more abundant vegetation (Humphrey and Sneath 1999). In practice, these different pasture use systems often lie next to each other (Humphrey and Sneath 1999).

Here, we developed a simple model that employs key environmental factors to propose a threshold mechanism that can be used to distinguish between equilibrium and nonequilibrium pasture use systems, using Mongolian rangeland as an example.

\section{METHODS}

Mongolia is a landlocked country in northeastern Asia. It borders on the Russian taiga area in the north, where the mean annual precipitation is more than $400 \mathrm{~mm}$, but borders on Chinese arid deserts in the south, where the mean annual precipitation is less than $50 \mathrm{~mm}$. Therefore, a steep climatic gradient exists from north to south. Currently, $74 \%$ of the territory is agricultural land, of which $97 \%$ is used as pasture (National Statistical Office of Mongolia 2007). All pastures are owned by the state, and herders can legally move to any pasture so long as they can cover the cost of relocation, although sometimes local governments must intervene to resolve conflicts among herders. The region's climatic variations, combined with the long-term dominance of nomadic pastoralism, make the area suitable for a study of regional differences in pastoral systems in the context of equilibrium and nonequilibrium dynamics. 
Herders in nonequilibrium rangeland generally do not move if vegetation is sufficiently abundant to support their animals; they move only when there is insufficient vegetation (Humphrey and Sneath 1999). Therefore, we hypothesized that identifying areas where vegetation was insufficient to sustain livestock was the key to understanding the grazing systems of these herders. To do this, we calculated the minimum amount of biomass that could sustain a 40-kg nonpregnant and nonlactating sheep, the dominant livestock species in Mongolia, and compared this value with estimates of the maximum annual biomass derived from the maximum annual value of the normalized-difference vegetation index (NDVI). From these comparisons, we identified a threshold value of the NDVI that could separate pixels for which maximum annual biomass was above or below the level required to sustain sheep live weight. Next, we compared the NDVI of each pixel from the satellite images with the threshold NDVI in order to map the probability that herders would withdraw from an area of rangeland and move to a new area on the basis of the following assumption: if the NDVI estimated from satellite images is less than the threshold value, herders are likely to move to a new area of rangeland. Subsequently, we examined the distribution of biomass in relation to climatic zones that we defined on the basis of annual rainfall.

Next, we derived NDVI data from 2000 to 2008 by using the Terra MODIS 1-km monthly composite NDVI dataset (US Geological Survey, Land Process Distributed Active Archive Center 2009). We determined the annual maximum NDVI value for each pixel.

Because food intake is regulated by forage availability at low biomass levels, a biomass threshold can be postulated at which the energy provided by the daily food consumption equals that required to sustain the animal's weight. When livestock are present in a pasture with more biomass than this threshold, the livestock gain weight; when the biomass is below this threshold, they lose weight. We therefore assumed that this threshold biomass represents the key decision factor that herders used to decide whether they should leave an area of rangeland or stay; that is, rangeland with biomass levels below this threshold would be perceived as unsuitable by most herders. We derived the minimum energy requirement to sustain sheep weight from data from the National Research Council (1981). This value equaled $0.389 \mathrm{MJ} \cdot$ livestock weight $(\mathrm{kg} ; \mathrm{LW})^{0.75} \mathrm{~d}^{-1}$. We derived the metabolizable energy provided by Mongolian rangeland from data provided by Hiroshi Nakamura (personal communication, September 2009), in which all species in sampling plots in Selenge and Dundgovi provinces in June 2009 were combined. Three $1 \times 1 \mathrm{~m}$ plots were selected in typical steppe vegetation in Selenge Province and another three plots in typical desert steppe in Dundgovi Province (six plots in total) were selected independent of this study. The metabolizable energy of the samples was measured at the Mongolian State University of Agriculture. The simple average value for these sampling plots was $7.7 \mathrm{MJ} \cdot \mathrm{kg}^{-1}$. Therefore, the quantity of plant dry matter required to sustain a single sheep would be $50.5 \mathrm{~g} \cdot \mathrm{LW}^{0.75} \mathrm{~d}^{-1}$. We used the results of four previous case studies of food intake efficiency (Leigh and Mulham 1966; Wilson et al. 1969; Noble 1975; Short 1985) to provide the relationships between food consumption and vegetation biomass. We calculated the threshold biomass for each of the four studies by finding the biomass at which the food intake rate equaled the quantity of plant dry matter required to sustain a sheep for $1 \mathrm{~d}$. We averaged the four threshold biomasses from these studies to obtain a value of $355.1 \mathrm{~kg} \cdot \mathrm{ha}^{-1}$. In the final step of this analysis, we used the regression equation that Yamamoto et al. (2000) developed for Mongolian grassland to estimate the annual maximum biomass on the basis of the annual maximum NDVI. From this analysis, we determined that an annual maximum NDVI value of at least 0.342 was required to sustain a sheep's weight.

We obtained rainfall data from 2000 to 2008 from the US Department of Commerce, National Climatic Data Center (2009) between latitudes $39^{\circ} \mathrm{N}$ and $55^{\circ} \mathrm{N}$ and between longitudes $84^{\circ} \mathrm{E}$ and $123^{\circ} \mathrm{E}$ to cover all of Mongolia. To create an annual rainfall map, we interpolated annual rainfall for each point in a $1 \times 1 \mathrm{~km}$ grid as root-mean-square values for the four nearest data points, averaged these annual values for the 2000-2008 period, and classified the resulting grid into $25-\mathrm{mm}$ intervals for average annual rainfall to define climate zones. For each climate zone, we determined the probability distribution for the maximum annual NDVI by using data from 2000-2008, and classified the climate zone as "equilibrium" or "nonequilibrium" if the modal value was, respectively, above or below the threshold of 0.342 . To examine the stability of this overall classification, we calculated the proportion of pixels below the threshold in each climate zone in each year. We then compared the results (i.e., whether herders remained stably in an area or moved their herds to follow rainfall patterns) with those of previous studies of herder movement patterns in Mongolia.

\section{RESULTS}

Figure 1 presents the probability function for NDVI for each range of rainfall values (i.e., for the rainfall-based climate zones). Note that the $y$-axis represents the product of NDVI and the probability function for NDVI, $\mathrm{p}(\mathrm{NDVI})$, because the $x$-axis has a logarithmic scale. Here, $\mathrm{p}(\mathrm{NDVI})=\mathrm{dP}(\mathrm{NDVI}) /$ dNDVI, where $\mathrm{P}(\mathrm{NDVI})$ is the cumulative probability function, and $\mathrm{p}(\log \mathrm{NDVI})=\mathrm{dP}(\log \mathrm{NDVI}) / \mathrm{d}(\log \mathrm{NDVI})=\mathrm{p}(\mathrm{NDVI})[\mathrm{dNDVI} /$ $\mathrm{d}(\log \mathrm{NDVI})]=\mathrm{p}(\mathrm{NDVI}) \times \mathrm{NDVI}$. As rainfall increases, the modal NDVI value gradually increases. The threshold NDVI corresponding to the biomass that meets the minimum requirement of the livestock $(0.342)$ is provided as a reference point in this figure. The position of the modal NDVI values suggests that the threshold between climate zones lies between two rainfall classes: $150-175 \mathrm{~mm}$ and $175-200 \mathrm{~mm}$. For climatic zones with more than $175 \mathrm{~mm} \cdot \mathrm{yr}^{-1}$ of rainfall, the modal NDVI is greater than the threshold NDVI, which means that most of the area has sufficient food to sustain sheep weight. Therefore, we defined the climate zones with modal NDVIs below the threshold as below-threshold zones and those with modal NDVIs above the threshold as above-threshold zones. Figure 2 shows the mean NDVI and coefficient of variation $(\mathrm{CV})$ of NDVI for each climate zone. The average NDVI increases continuously as rainfall increases, and the CVs of NDVI were similar across climate zones. 

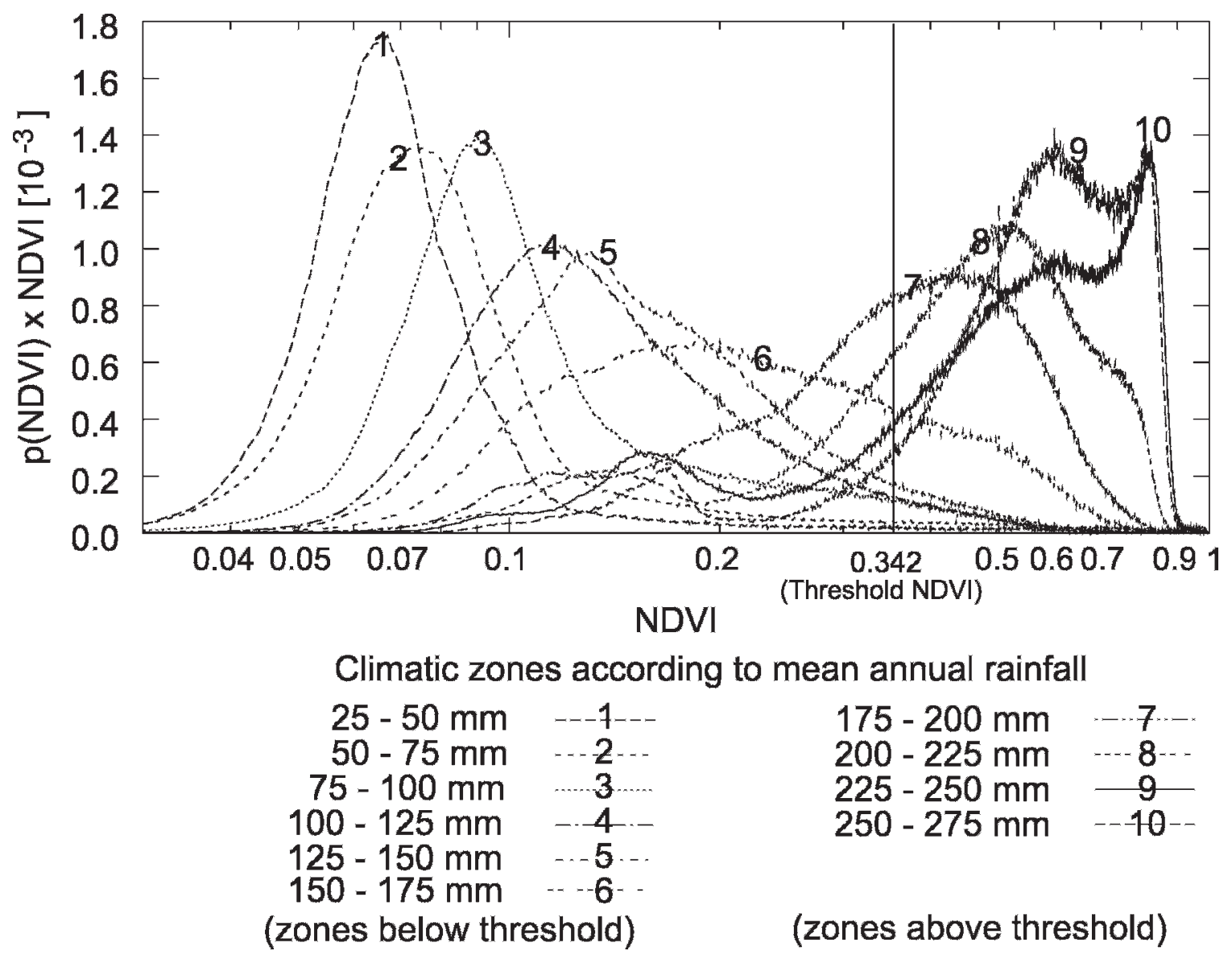

Figure 1. Probability functions for normalized-difference vegetation index (NDVI; i.e., p[NDVI]) for each climatic zone, with the zones defined in 25$\mathrm{mm}$ annual precipitation intervals for mean annual rainfall from 2000 to 2008 . The threshold NDVI (0.342) is the value that corresponds to the minimum biomass required to sustain sheep weight. As mean annual rainfall increases, the modal NDVI increases (moves to the right side of the figure).

Figure 3 shows the proportion of the cells in the grid with NDVI levels below the threshold value from 2000 to 2008. For zones with rainfall of less than about $125 \mathrm{~mm}$, the proportion of the zone that was unsuitable for livestock grazing (i.e., with a value below the threshold) remained relatively constant between years and was greater than 0.9 (Fig. 3).

Figure 4 is a map of the above-threshold zones (white regions) and below-threshold zones (gray regions) throughout Mongolia.

\section{DISCUSSION}

In all rainfall zones, the range of NDVI values (used as a proxy for biomass) and the CV (Fig. 2) were similar. The spatiotemporal pattern of biomass variation therefore exhibited no substantial qualitative or threshold differences, but rather a continuous change among the climate zones.

Comparison of the modal NDVI value with the threshold required to sustain livestock, however, provided a clear distinction between the climate zones. In above-threshold zones, our hypothesis suggests that most rangeland would be suitable for grazing; therefore, herders could continue to use this area steadily as pasture, except during unusual droughts. In contrast, rangeland in below-threshold zones would frequently be unsuitable for grazing; therefore, herders would favor opportunistic movement of their animals to better pastures. Figure 3 exhibits a threshold pattern in the increase in the area of suitable pasture as rainfall increases, with this proportion increasing much more rapidly as mean annual rainfall increased above 100-125 mm, and with the proportion of unsuitable pasture decreasing below 0.5 with annual rainfall greater than 150-175 mm. Next, we determined whether areas with rainfall greater than or lower than this threshold corresponded to areas where herders followed steady (equilibrium) or opportunistic (nonequilibrium) management patterns.

Figure 4 identifies regions where the modal NDVI value is below the threshold and we would expect opportunistic management to predominate. Although there have been few previous studies of this region, those that we found generally supported our predictions. Humphrey and Sneath (1999) classified the Mongolian pastoral systems described by Bazargur et al. (1989) and the precollective pastoral systems described by Simukov (1934). Here, we do not discuss all of the system types because of their complexity. Humphrey and Sneath (1999) noted that the Ar-Hangai and Hentii systems in the classification of Bazargur et al. (1989) resemble the Hangai type of Simukov's (1934) classification, in which herders carry out steady seasonal movement within the pastures for which they have a customary right of exclusive use, because the amount of 


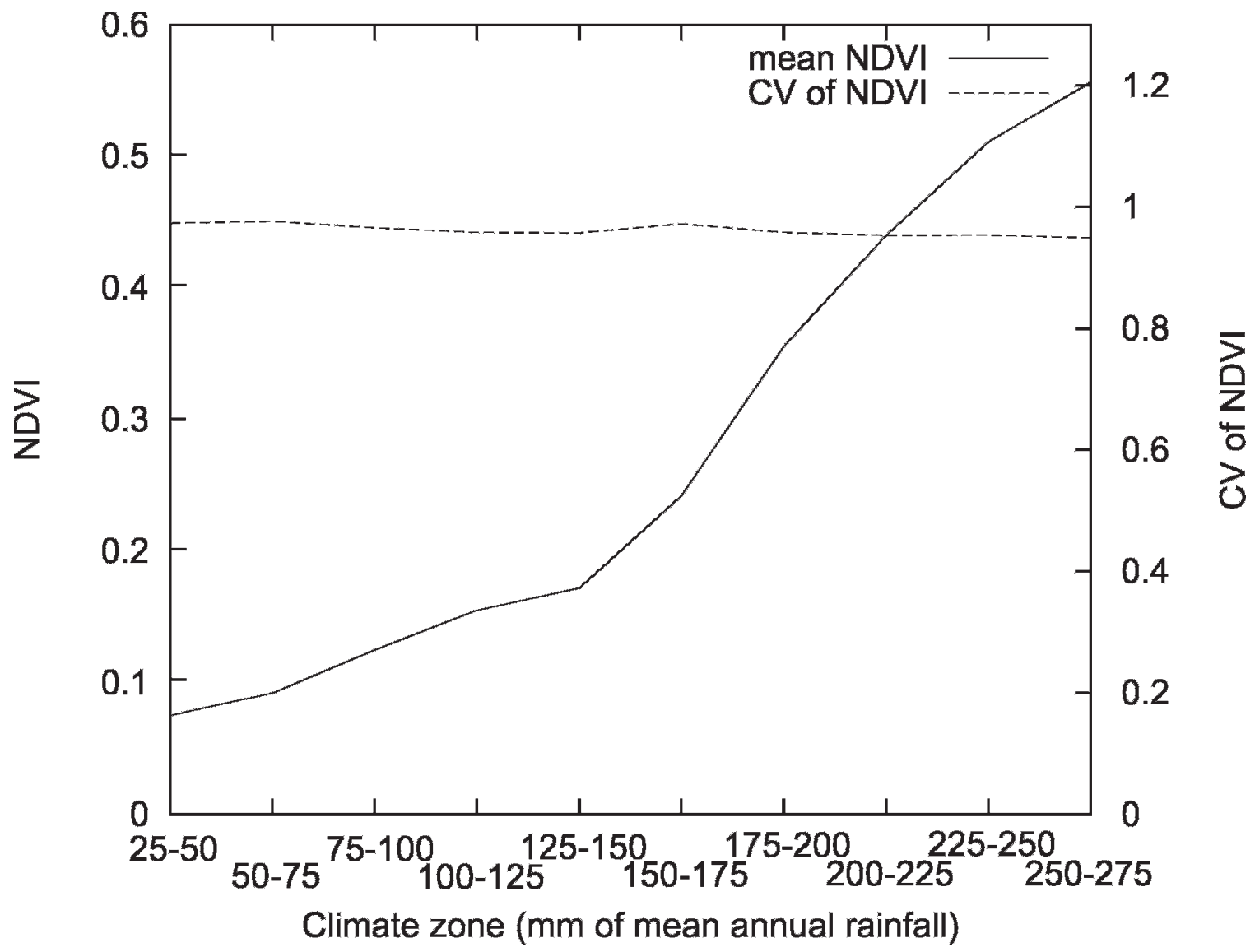

Figure 2. Mean normalized-difference vegetation index (NDVI) and coefficients of variation (CVs) for the NDVI values for each climate zone (based on mean annual rainfall using data from 2000 to 2008).

vegetation remains constant. These descriptions suggest that ArHangai and Hentii provinces are locations where the steady management system is used, and this confirms our predictions in Figure 4. Conversely, the Dornogovi type in the classification of Bazargur et al. (1989) and the Gobi type in Simukov's (1934) classification correspond to opportunistic management patterns based on the description by Humphrey and Sneath (1999), who noted that herders move in response to changing rainfall conditions. It is apparent that Dornogovi Province can be classified as a below-threshold zone; this again confirms our predictions. Okayasu et al. (2008) interviewed herders in Dundgovi Province and learned that they had no individual or group summer pastures and instead moved to rangeland where it had recently rained. This is a typical opportunistic management system, and our predictions again showed that Dundgovi Province was within the below-threshold zone (Fig. 4).

These comparisons led us to conclude that the boundary we defined between steady and opportunistic management broadly agreed with previous research results, and this supported our hypothesis that whether rangeland possessed sufficient biomass to sustain livestock weight was the key determinant of the rangeland management regime adopted by herders in different regions of Mongolia. One of the key implications of our results is that thresholds can appear even under a continuous climatic gradient. Coppock (1993) provides another example of a process that reveals threshold behavior even in the presence of a continuous natural environment. Coppock defined the location of nonequilibrium environments by comparing the interval between droughts with the time required for animal populations to recover after a drought (the "restocking speed"). According to his description, arid rangeland exists in a nonequilibrium state because drought occurs again before animal numbers have fully recovered, whereas animal numbers in humid rangeland can recover before the next drought; this results in a density-dependent animal-vegetation interaction. The intervals of drought change continuously along a climatic gradient, but the restocking speed introduces a specific time scale that results in threshold behavior (i.e., whether animals can fully recover to predrought levels).

The threshold behavior suggests that it is important to monitor the location of the boundary between the two types of pasture use system to detect times when climatic change causes movements in the position of this boundary. Batimaa et al. (2005) examined long-term climatic data for all of Mongolia and found that the trends in temperature and rainfall varied spatially. National governments and aid agencies must understand the meaning of thresholds and must identify focal areas where thresholds exist, requiring changes in the management regime, so they can develop appropriate policies for each region that will support herders in the long term. Our study provides a simple, inexpensive way to identify such thresholds and evaluate them as a region's climate changes.

The most commonly recognized boundary between equilibrium and nonequilibrium environments is the $33 \%$ isoline for 


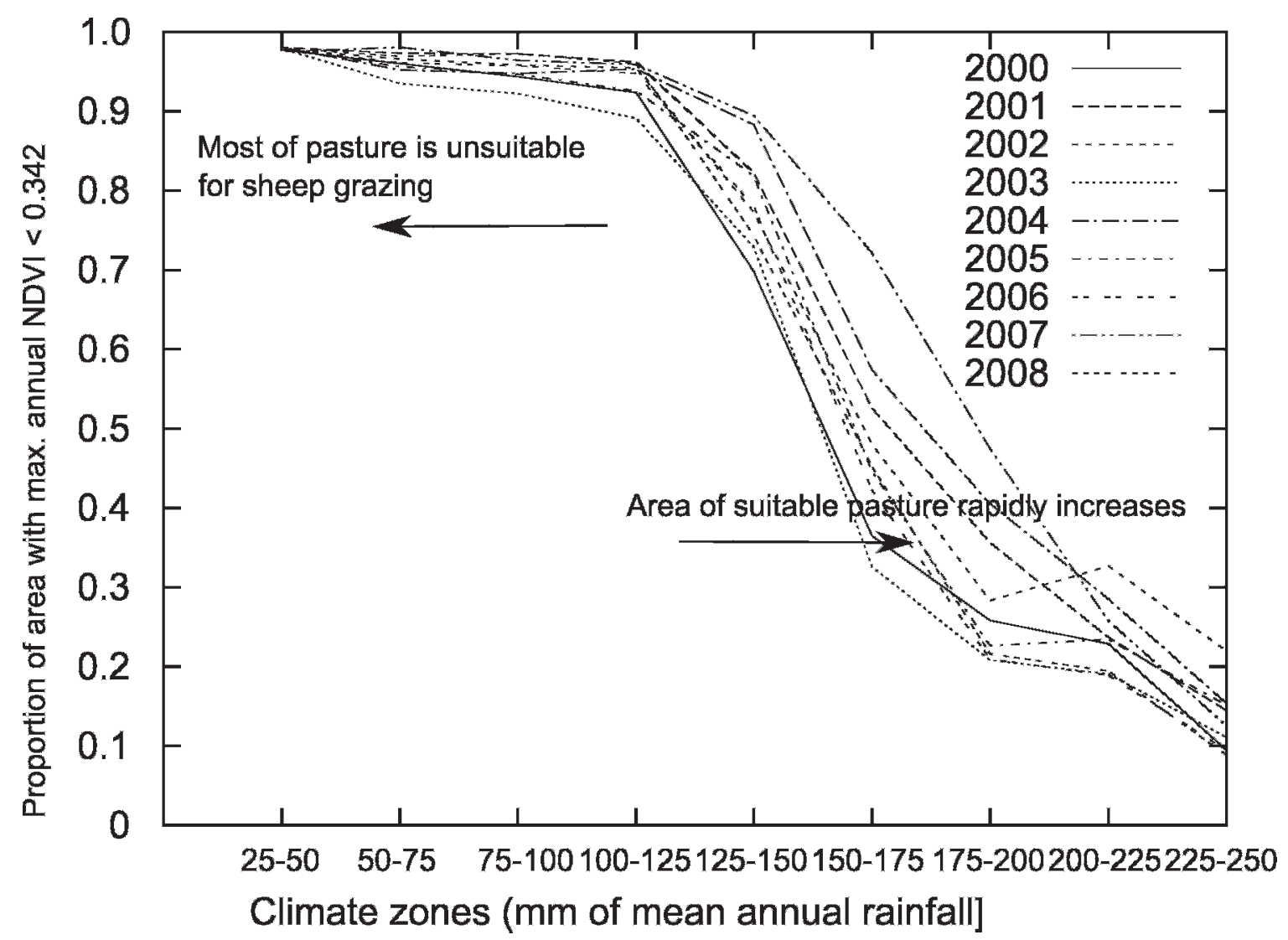

Figure 3. Proportion of the grassland area of Mongolia with biomass below the minimum level (i.e., the threshold) required to sustain sheep weight as a function of the mean annual rainfall from 2000 to 2008. At low rainfall levels, most of the pasture is unsuitable for sheep grazing, whereas at high rainfall $(>125 \mathrm{~mm})$, the proportion of suitable pasture increases rapidly with increasing rainfall. The trends were stable throughout the study period.

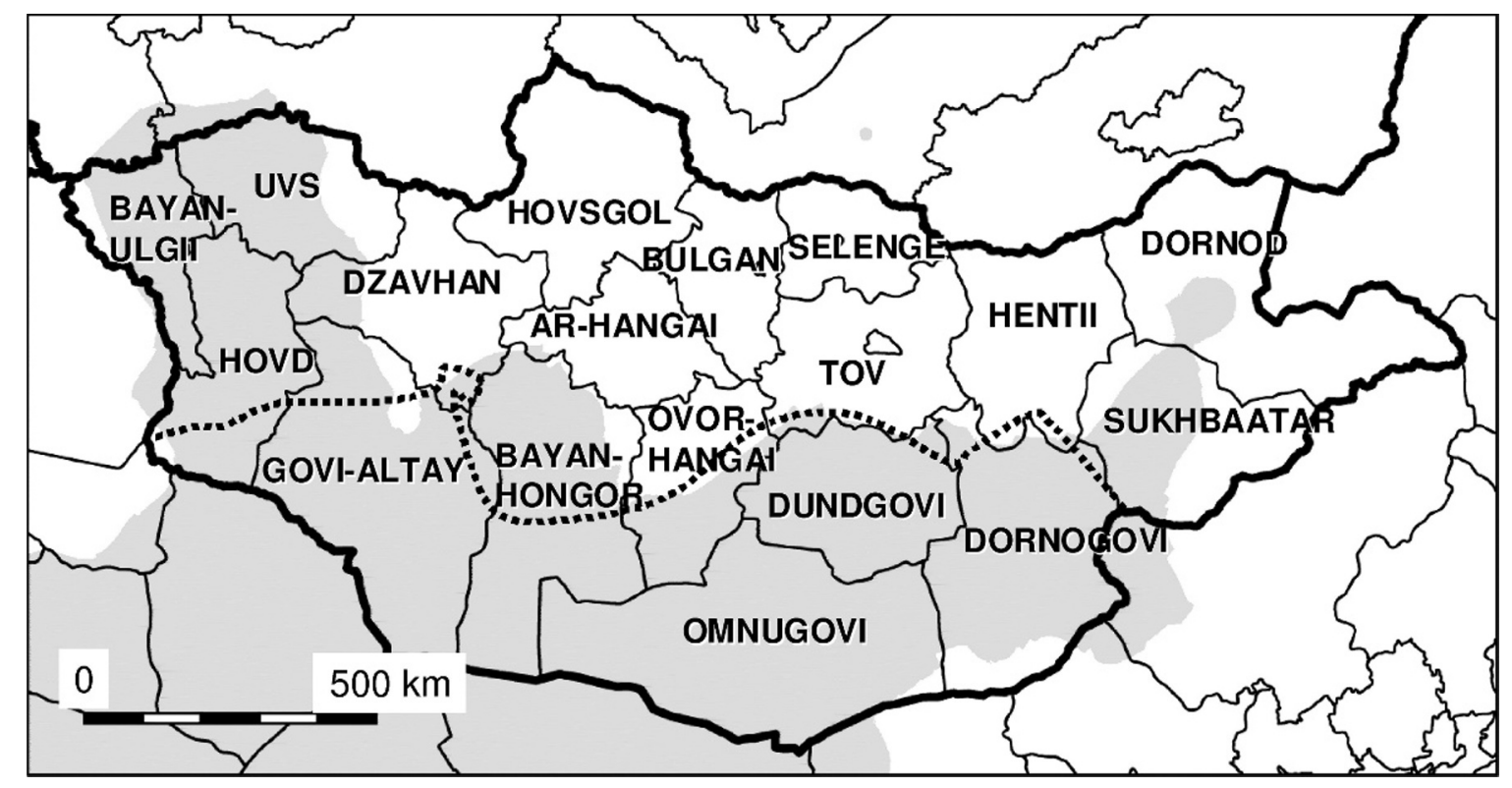

Figure 4. Map of the climate zones in which the modal value of the normalized-difference vegetation index (NDVI) histogram in Figure 1 is below the threshold NDVI value (0.342) that corresponds to the minimum biomass required to sustain sheep weight. Areas with insufficient biomass (below-threshold zones) are shaded in gray. The province boundaries and names are included as references for locations described in the paper. The dotted line represents the $33 \%$ coefficient of variation (CV) isoline for annual rainfall, based on the data of Humphrey and Sneath (1999). The areas south of the dotted line have a CV $>33 \%$. The $33 \%$ CV isoline and the boundaries of the management systems estimated in this study generally agreed, but differed most in the western provinces. 
the CV of annual rainfall. This value has frequently been referred to in previous studies of nomadic pastoralism (e.g., Ellis 1996; Humphrey and Sneath 1999; Uemura 2004). The boundary derived in our study follows the $33 \% \mathrm{CV}$ isoline for annual rainfall calculated by Humphrey and Sneath (1999) in most of southern Mongolia (Fig. 4). In eastern Mongolia, the isoline generally agreed well with our estimated boundary, apart from a small area of unsuitable pasture in Sukhbaat and Dornod provinces, whereas most of northwestern Mongolia (particularly Hovd, Bayan Ulgii, and Uvs provinces and part of Dzavhan Province) was below the threshold; this was not predicted by the CV isoline. Because the $33 \% \mathrm{CV}$ isoline of Humphrey and Sneath (1999) was based on climatic data from the 20th century, we cannot determine why the CV isoline prediction disagreed with the results of our study; however, it is possible that this resulted either from differences in the data collection periods (e.g., differences from the long-term climatic averages that occurred during the past 8 yr or so) or from differences in the target process (rainfall fluctuation vs. frequency of sufficient vegetation).

If the former explanation is correct, this suggests that northwestern Mongolia has changed from an equilibrium environment to a nonequilibrium environment; this emphasizes the importance of monitoring the boundary between equilibrium and nonequilibrium environments when climate conditions change. If the latter explanation is correct, the difference may have resulted from the lack of a strong correlation between the annual fluctuations in rainfall and the abundance of biomass; that is, rainfall in the northwestern regions might be relatively stable at a low level. Generally, the CV of annual rainfall increases as rainfall decreases (Nicholls and Wong 1990). But if this relationship is not correct for northwestern Mongolia, that area would be expected to differ to some extent from the predictions based on the isoline. The current debate over the relative importance of equilibrium and nonequilibrium conditions implicitly assumes that all relevant climatic factors change in parallel along a climatic gradient, probably because of the assumed large spatial scale and to keep the debate simple. However, deviations could naturally occur if two or more climatic parameters show different trends in part of a study area or during a specific period. If this explanation is correct, it suggests that a multifactor consideration of climatic variation and its effect on pasture dynamics will be necessary before concrete implementation of our study results on a local scale.

Our study had several limitations. First, it was somewhat hypothetical. Although the results were consistent with those of the few previous studies we were able to find, more detailed studies to compare the herders' actual movement patterns with vegetation conditions will ultimately be required to validate our hypothesis. Although several studies have integrated equilibrium and nonequilibrium environments in terms of animal and vegetation dynamics, no studies have explicitly provided an integrated view of patterns of steady and opportunistic management. In addition, no empirical studies have investigated how pasture use systems change along a climatic gradient or have investigated whether a continuous relationship or a threshold exists. Another difficulty in evaluating our results is that even though there have been some studies of the impact of vegetation changes on herders as a result of climatic control of the vegetation (Fernandez-Gimenez and Allen-Diaz 1999;
Stump et al. 2005; Zemmrich 2007), there have been no studies that have simultaneously investigated the herders' pasture use pattern and the vegetation impact caused by grazing. Other limitations include the fact that we assumed that sheep were the only livestock, even though many camels capable of tolerating high levels of aridity are grazed in arid regions of Mongolia. Economic factors may also affect management patterns, because herders must weigh the costs and benefits of the decision to move or stay. Therefore, further interdisciplinary studies should be conducted to improve our understanding of the factors responsible for the delineation of equilibrium and nonequilibrium environments.

We developed our model by comparing the biomass distribution in Mongolia with the minimum biomass required to sustain sheep weight. This was the first study to attempt a quantitative estimation of the border between steady and opportunistic management on the basis of the underlying processes. We concluded that identifying a rainfall threshold at which the modal value of maximum annual NDVI (used here as a proxy for the maximum annual biomass) is above or below the minimum value required to sustain livestock, which can help managers to distinguish between regions where steady vs. opportunistic management is expected to dominate.

\section{IMPLICATIONS}

This study provided a quantitative estimate of the location of a boundary (based on rainfall) at which the most suitable rangeland management options and interventions should change. Currently, such boundaries have been identified empirically from rough tracking of the movement of herders. Our study therefore provides a starting point from which it will be possible to develop appropriately detailed zoning at lower cost than is possible with competing methods, both under the current situation and in a future environment that is predicted to change drastically in response to global warming. The threshold behavior that we observed suggests that it is important to monitor the locations of the boundaries between pasture use systems to detect changes in these boundaries in response to climatic change. Temperature and rainfall trends vary spatially in Mongolia (Batimaa et al. 2005), emphasizing the importance of such monitoring. Understanding the processes that determine the most appropriate zoning for rangeland management will enable managers to predict the most appropriate rangeland management policies and interventions and will provide more flexible alternatives. National governments and aid agencies must understand the importance of threshold processes so that they can identify focal areas where management change is required and can develop appropriate policies for each region to support herders in the future. Our approach provides a simple, low-cost tool that will support the development of comprehensive policies and effective interventions to support herders at national or regional scales.

\section{ACKNOWLEDGMENTS}

We thank the editors and the reviewers who provided detailed critiques of the form, content, and logic of our paper, and thereby improved its quality. 


\section{LITERATURE CITED}

Batimaa, P., B. Bat, and T. Terendorj. 2005. Observed climate change in Mongolia. Ulaanbaatar, Mongolia: Assessments of Impacts and Adaptations to Climate Change Working Paper 12. 26 p. Available at: http://www.aiaccproject.org/ working_papers/working_papers.html. Accessed 1 December 2010.

Bazargur, D., S. Chinbat, and S. Shilrev-Ad'yaA. 1989. Bugd nairamdah mongol ard ulsyn malchdyn nuudel [The movement of pastoralists of the Mongolian People's Republic]. Ulaanbaatar, Mongolia: State Publishing House. 217 p. [In Mongolian.]

Behnke, R. H., JR., AND I. Scoones. 1993. Rethinking range ecology: implications for rangeland management in Africa. In: R. H. Behnke, Jr., I. Scoones, and C. Kerven [EDS.]. Range ecology at disequilibrium: new models of natural variability and pastoral adaptation in African savannas. London, United Kingdom: Overseas Development Institute. p. 1-30.

Briske, D. D., S. D. Fuhlendorf, and F. E. Smeins. 2003. Vegetation dynamics on rangelands: a critique of the current paradigms. Journal of Applied Ecology 40:601-614.

CAughley, G. 1979. What is this thing called carrying capacity? In: M. S. Boyce and L. D. Hayden-Wing [EDS.]. North American elk: ecology, behavior and management. Laramie, WY, USA: University of Wyoming Press. p. 2-8.

CLementS, F. 1916. Plant succession: an analysis of the development of vegetation. Washington, DC, USA: Carnegie Institute Publications. 512 p.

Coppock, D. L. 1993. Vegetation and pastoral dynamics in the Southern Ethiopian rangelands: implications for theory and management. In: R. H. Behnke, Jr., I. Scoones, and C. Kerven [EDS.]. Range ecology at disequilibrium: new models of natural variability and pastoral adaptation in African savannas. London, United Kingdom: Overseas Development Institute. p. 42-61.

Danckwerts, J. E., P. J. O'Reagain, and T. G. O'Connor. 1993. Range management in a changing environment: a southern African perspective. Rangeland Journal 15:133-144.

Eluıs, J. E. 1996. Climate variability and complex ecosystem dynamics: implications for pastoral development. In: I. Scoones [ED.]. Living with uncertainty: new directions in pastoral development in Africa. London, United Kingdom: Intermediate Technology Publications. p. 37-46.

Ellis, J. E., AND D. M. Swift. 1988. Stability of African pastoral ecosystems: alternative paradigms and implications for development. Journal of Range Management 41:458-459.

Fernandez-Gimenez, M. E., and B. Allen-Diaz B. 1999. Testing a non-equilibrium model of rangeland vegetation dynamics in Mongolia. Journal of Applied Ecology 36:871-885.

Fiedler, P. L., P. S. White, And R. A. Leidy. 1997. The paradigm shift in ecology and its implications for conservation. In: S. T. A. Pickett, R. S. Ostfeld, M. Shachak, and G. E. Likens [EDS.]. The ecological basis for conservation-heterogeneity, ecosystems and biodiversity. New York, NY, USA: Chapman and Hall. p. 83-92.

Hary, I., H. J. Schwarz, V. H. C. Pielert, and C. Mosler. 1996. Land degradation in African pastoral systems and the destocking controversy. Ecological Modelling 86:227-233.

Humphrey, C., and D. Sneath. 1999. The end of nomadism? Society, state and the environment in inner Asia. Durham, NC, USA: Duke University Press. 355 p.

IluIus, A. W., AND T. G. O'Connor. 1999. On the relevance of non-equilibrium concepts to arid and semiarid grazing systems. Ecological Applications 9:798-813.

LeIGH, J. H., AND W. Mulham. 1966. Selection of diet by sheep grazing semi-arid pastures on the Riverine plain. 1. A bladder saltbush (Atriplex vesicaria)- cotton bush (Kochia aphylla) community. Australian Journal of Experimental Agriculture and Animal Husbandry 6:460-467.

National Research Council. 1981. Nutritional energetics of domestic animals and glossary of energy terms. Washington, DC, USA: National Academy Press. $54 \mathrm{p}$.

National Statistical Office of Mongolia. 2007. Mongolian statistical yearbook 2006. Ulaanbaatar, Mongolia: National Statistical Office of Mongolia. $401 \mathrm{p}$.

Nicholls, N., AND K. K. Wong. 1990. Dependence of rainfall variability on mean rainfall, latitude and the southern oscillation. Journal of Climate 3:162-170.

Noble, I. R. 1975. Computer simulations of sheep grazing in the arid zone [thesis]. Adelaide, Australia: University of Adelaide. $308 \mathrm{p}$.

Okayasu, T., H. Nakamura, and K. Takeuchi. 2008. Possible countermeasures to combat desertification and drought in a desert-steppe region of Mongolia. Journal of Environmental Information Science 36:141-150.

Perevolotsky, A. 1987. Territoriality and resource sharing among the Bedouin of southern Sinai: a socio-ecological interpretation. Journal of Arid Environments 13:153-161.

SCOONES, I. 1996. New directions in pastoral development in Africa. In: I. Scoones [ED.]. Living with uncertainty: new directions in pastoral development in Africa. London, United Kingdom: Intermediate Technology Publications. p. $1-36$.

SHORT, J. 1985. The functional response of kangaroos, sheep and rabbits in an arid grazing system. Journal of Applied Ecology 22:435-447.

Simukov, A. D. 1934. Mongol'skii Kochevki [Mongolian migrations]. Sovremennaya Mongoliya [Contemporary Mongolia] 4:40-46. [In Russian.]

Stump, M., K. Wesche, V. Retzer, and G. Mlehe. 2005. Impact of grazing livestock and distance from water source on soil fertility in southern Mongolia. Mountain Research and Development 25:244-251.

Sullivan, S., And R. Rohde. 2002. On non-equilibrium in arid and semi-arid grazing systems. Journal of Biogeography 29:1595-1618.

Uemura, A. 2004. Posuto shakai shugi mongoru kokuno bokuchikuni okeru tochiriyo [Land use for stock raising in post-socialist Mongolia]. Mongoru hou kenkyuukai (Symposium on Mongolian law studies); 17 July 2004; Nagoya, Japan. Nagoya, Japan: Mongoru hou kenkyuukai (Symposium on Mongolian law studies). p. 1-24. [In Japanese.]

us Department of Commerce, national Climatic Data Center. 2009. Global surface summary of day. Available at: http://lwf.ncdc.noaa.gov/cgi-bin/res40.pl?page = gsod.html. Accessed 4 July 2009.

US Geological Survey, Land Process Distributed Active Archive Center. 2009. MODIS product table. Available at: https://lpdaac.usgs.gov/lpdaac/products/ modis_products_table. Accessed 4 July 2009.

Watson, I. W., D. G. Burnside, and A. M. Holm. 1996. Event-driven or continuous; which is the better model for managers? Rangeland Journal 18:351-369.

Wilson, A. D., J. H. Leigh, and W. E. Mulham. 1969. A study of merino sheep grazing a bladder saltbush (Atriplex vesicaria)-cotton bush (Kochia aphylla), community on the riverine plain. Australian Journal of Agricultural Research 20:1123-1126.

Yamamoto, H., K. Kajiwara, and Y. Honda. 2000. The study on biomass estimation in Mongolian grassland using satellite data and field measurement data [poster session]. In: Proceedings of the Asian Conference on Remote Sensing; 4-8 December 2000; Taipei, Taiwan. Taipei, Taiwan: Asian Conference on Remote Sensing. PS200-8.

Zemmrich, A. 2007. Equilibrium or non-equilibrium ecosystems? Scaling effects in rangeland ecosystems of western Mongolia. Erdkunde 61:335-343. 